\title{
Od vizualne kulture do vizualne pismenosti - vizualnost u medijima i etička odgovornost medijskih publika u digitalnom dobu
}

Leali Osmančević ${ }^{*}$

leali.osmancevic@unicath.hr

https://orcid.org/0000-0002-2377-2332 https://doi.org/10.31192/np.19.1.13

UDK: 316.774-028.22

179:316.774

Pregledni članak / Review

Primljeno: 12. svibnja 2020.

Prihvaćeno: 4. rujna 2020.

Vizualnost je u digitalnom dobu jedno od glavnih obilježja slanja poruka od pošiljatelja do primatelja informacije $i$ vizualnog sadržaja. Stoga, i sam vizualni medijski narativ aktualna je tema u digitalnom dobu, zbog svoje brzine prijenosa, naklonjenosti čovjeka vizualnim sadržajima te percepcije društvene stvarnosti temeljene na vizualnosti. Slijedom toga, nameće se pitanje uloge $i$ važnosti etike u vizualnoj eri masovnog odašiljanja informacija, kao i razvoja vizualne pismenosti medijskih publika. Zbog različitih interesa, medijske publike, radi što odgovornijeg pristupa razumijevanju vizualnih medijskih sadržaja, potaknute su da razvijaju sposobnost vizualnog opismenjivanja, uz srodnu medijsko-informacijsku pismenost (eng. MIL). U radu će biti pojašnjeni temeljni pojmovi vizualne kulture, vizualnih medija i vizualnog framinga, kao i uloga medijskih publika u razumijevanju i razlikovanju medijskog prikaza društvene stvarnosti od strane medijski konstruirane stvarnosti. Propitivat će se $i$ važnost integriranja etike u proces odašiljanja, primanja vizualnih medijskih sadržaja koji, uz pomoć različitih sastavnica, pridonose jačanju odgovornosti i napretku društva.

Ključne riječi: etika, medijske publike, vizualna kultura, vizualni narativ, vizualna pismenost.

\footnotetext{
* Leali Osmančević, mag. comm., asistentica, Hrvatsko katoličko sveučilište, Odjel za komunikologiju, Ilica 242, HR-10000 Zagreb.
} 


\section{Uvod}

Masovne medije nemoguće je definirati bez obilježja vizualnosti te stvarati »frame«, odnosno okvir unutar kojeg će primatelji (multi)medijskih sadržaja percipirati, interpretirati i stvarati mišljenje na temelju dobivenih informacija o nekom događaju. ${ }^{1}$ Etika, kao filozofska disciplina s obilježjem univerzalnosti, isključuje odstupanja od etičkih normi te definira etički ispravnu od neispravne ili neprofesionalne vizualne kulture kao i prakse vizualnih medija. Uzimajući u obzir da su ljudi vizualna bića i da je vizualna komponenta medijskoga teksta dio navedene komponente koja većinom "govori više od tisuću riječi«, teme vizualnosti, vizualne kulture i vizualnog narativa u medijima aktualne su i nepresušne, kako u javnosti i javnome društvenom govoru tako i u znanstveno-istraživačkim i akademskim krugovima i u interdisciplinarnim pristupima unutar društveno-humanističkih znanosti, poput povijesti umjetnosti i književnosti. U digitalnom dobu, vizualnost je postala jedno od presudnih obilježja i za sam opstanak nekog medija zbog privlačenja pozornosti i interesa medijskih publika te je u tom kontekstu usko vezana uz pojam etike vizualnosti, kao i vizualne pismenosti, jedne od ključnih sastavnica medijske, odnosno medijskoinformacijske pismenosti (eng. Media and Information Literacy - MIL). ${ }^{2}$

Vizualna kultura je dio filozofskog i antropološkog promišljanja, komunikacijskih i medijskih studija, kao što su oglašavanje i filmska umjetnost te cjelokupna kultura temeljena na vizualnosti koja primatelju medijskog sadržaja omogućava vizualni prikaz u procesu masovne komunikacije. Taj proces odnosi se na proizvodnju medijskog sadržaja kao temelja, na pristup medijskih publika, odnosno recepcije, na postizanje ciljeva medijskih sadržaja kroz obilježje vizualnosti te u najširem poimanju, na ispunjavanje šireg društvenog i kulturalnog konteksta. Vizualna kultura i razumijevanje vizualnog narativa u društvu, s naglaskom na razvijena i demokratska društva, pridonosi jačanju društvene odgovornosti te omogućuje percepciju, kritičnost i osnaživanje društvene stvarnosti te povećava kritičnost kao temeljnu sposobnost odgovornih medijskih publika i time jasno određuje granicu između medijskog prikaza društvene stvarnosti i medijski konstruirane stvarnosti. ${ }^{3}$ Cilj ovoga rada je da pregledom recentne i relevantne znanstvene i stručne literature, s naglaskom na element vizualnosti i sam vizualni narativ, poveže etiku i vizualne medije te

${ }^{1}$ Usp. Darijo ČEREPINKO, Komunikologija. Kratki pregled najvažnijih teorija, pojmova i principa, Varaždin, Veleučilište, 2011.

2 Usp. David NATHARIUS, The more we know, the more we see. The role of visuality in media literacy, American Behavioral Scientist, 48 (2004) 2, 238-247, 239-240; https://unesdoc.unesco. org/ark:/48223/pf0000225606 (15.04.2020).

${ }^{3}$ Usp. Michael GRIFFIN, Images from nowhere. Visuality and news in $21^{\text {st }}$ century media, u: Volker DEPKAT, Meike ZWINGENBERGER (ur.), Visual Cultures - Transatlantic Perspectives, Publications of the Bavarian American Academy Series, Heidelberg, Universitätsverlag Winter, 2012, 159-220, 161-163. 
naglasi nužnost vizualnog opismenjavanja radi stvaranja kritične i odgovorne publike u digitalnom dobu.

\section{Etika $i$ vizualni narativ - terminologija vizualne kulture $i$ vizualnog framinga}

Vizualna kultura dio je multidisciplinarnog područja zbog različitih znanosti koje uključuje, od povijesti, arhitekture i antropologije, do sociologije, psihologije i komunikologije, kao i svih oblika umjetnosti. Pojam vizualno odnosi se na sve što može biti viđeno u različitim oblicima (fotografija, slika), što uključuje i vizualne podražaje u najširem smislu, a kultura na činjenicu da je vizualnost $u$ različitim formatima nezaobilazan dio kulture društva i njegova napretka te sveopćeg razvoja. ${ }^{4} \mathrm{U}$ kontekstu kulturoloških studija, autor Hunter promatra vizualnu kulturu kroz pojam estetike pa tako otvara pitanje o onome što se u vizualnoj kulturi smatra lijepim te ovo pitanje povezuje s filozofijom umjetnosti, dok kroz drugo pitanja razmatra što se to u vizualnoj kulturi smatra idealnim za društvo te potonje pitanje povezuje sa sociologijom, ali i etikom. ${ }^{5}$

Sva zapadna društva, pa prema tome i čitava zapadna kultura, zbog sve raširenijih načina prijenosa vizualnih sadržaja omogućenih digitalno-tehnološkim napretkom masovnih medija, žive $u$ takozvanoj okulocentričnosti kojom dominira vizualni format u svim sadržajima i time on postaje glavni izvor informacija - jedan od temeljnih elemenata profesionalnog i etičnog medijskog djelovanja u digitalnom, a samim time i vizualnom dobu. ${ }^{6}$ Vizualni mediji su sva sredstva ili skupovi sredstava koji se koriste za prijenos medijskih poruka, a koji imaju učinak na čovjekov osjet vida. ${ }^{7}$ Također, vizualni mediji uključuju sve vrste medija, od tradicionalnih do novih, mobilnih i digitalnih, jer je obilježje vizualnosti jedno od zajedničkih elemenata koji, bez obzira na načine korištenja, tehnoloških razlika i sl., privlače različite medijske publike koje s pomoću njih ostvaruju komunikaciju. ${ }^{8}$

Vizualna komunikacija koja se odvija putem vizualnih medija, a dio je vizualne kulture kao krovnog pojma i šireg područja, neodvojiva je od estetike kroz

${ }^{4}$ Usp. Paul E. BOLIN, Doug BLANDY, Beyond visual culture. Seven statements of support for material culture studies in art education, Studies in Art Education, 44 (2003) 3, 246-263.

${ }^{5}$ Usp. Ian HUNTER, Cultural Studies, u: Michael KELLY (ur.), Encyclopedia of Aesthetics, Oxford Art Online; http://oxfordartonline.com/subscriber/article/opr/t234/e0143 (15.04.2020).

${ }^{6}$ Usp. Anja STEVIĆ, Viktorija CAR, Vizualno portretiranje izbjeglica i migranata - ikonske fotografije, u: Viktorija CAR, Marijana MATOVIĆ (ur.), Mediji, novinarstvo i ljudska prava, Zagreb, Fakultet političkih znanosti Sveučilišta u Zagrebu i Zaklada Hanns-Seidel-Stiftung, 2017, 19-39, 23.

7 Usp. https://www.hrleksikon.info/definicija/vizualni-mediji.html (15.04.2020).

${ }^{8}$ Usp. Kenneth L. SMITH i dr. (ur.), Handbook of visual communication. Theory, methods, and media, New York - London, Routledge, 2004, 433. 
koju se i definira. Postoji nekoliko estetskih obilježja vizualne komunikacije i medija koji se mogu podijeliti u tri skupine. Ponajprije je riječ o onome što je vidljivo i strukturirano u vizualnoj komunikaciji i porukama posredovanim vizualnim medijima (1), potom uviđamo holistički pristup vizualnosti, ali i prijenosu i recepciji značenja koje vizualna poruka može imati (2) te kognitivno obilježje povezano $\mathrm{s}$ najširim kontekstom vizualne komunikacije i medija te sastavni dio vizualne kulture jer spaja tri značajne discipline: filozofiju, znanost i umjetnost, ali u širem kontekstu i nužnost znanstvenih istraživanja i proučavanja i umjetnost za razumijevanje estetskih elemenata vizualne kulture (3). $\mathrm{Za}$ cjelovito razumijevanje vizualne kulture nužno je poznavanje i prepoznavanje obilježja u svih triju skupina.

Pojam koji je izravno povezan s dosad spomenutim obilježjem vizualnosti je i vizualni framing, odnosno uokviravanje medijskih sadržaja. Framing, odnosno teorija o framingu je u medijskim studijama i komunikologiji teorija o uokviravanju koje se odnosi na smještaj prioritetnih tema u medijima, dok frame, odnosno okvir ili, svojevrsni kadar, čini okvir za interpretaciju koji kroz svijest novinara kao medijskog djelatnika utječe na olakšavanje procesa odabira i recepcije medijske informacije. ${ }^{9} \mathrm{U}$ kontekstu rada i vizualnog narativa, nužno je definirati i pojam vizualnog framinga, odnosno vizualnog uokviravanja sadržaja. Teorija o uokviravanju (eng. framing) se prije svega odnosi na analizu medijskih tekstova kroz propitivanje načina na koji su vizualni elementi medijskih sadržaja, uglavnom slike, korištene, ali i percipirane od strane medijskih publika, posebice jer su upravo takvi vizualni sadržaji postali sredstvom komunikacije, posebice $u$ digitalnom dobu. ${ }^{10}$

Vizualno uokviravanje odnosi se na vizualnu percepciju društvene stvarnosti koja ponajprije utječe na vizualne podražaje, a potom komunikatoru kao pojedincu unutar određene medijske publike omogućuje niz kompetencija. One uključuju analizu i interpretaciju vizualnog okvira informacija i integraciju vizualnih medijskih tekstova u percepciju društvene stvarnosti unutar kognitivnih struktura svakog od primatelja medijskih sadržaja. ${ }^{11}$ Jedan od temeljnih elemenata vizualnog uokviravanja su simboli i znakovi koji u najširem semiotičkom kontekstu sudjeluju u kreiranju prepoznatljivih društvenih mitova i narativa. Svojim brojnim značenjima pridonose vizualnoj prepoznatljivosti pošiljatelja i općenitom korištenju vizualnih alata koji smanjuju takozvane napore u recepciji medijskih sadržaja (primjerice tekstualnih). Na taj se način cijeli

\footnotetext{
${ }^{9}$ Usp. Čerepinko, Komunikologija...; Michael KUNCZIK, Astrid ZIPFEL, Uvod u znanost o medijima i komunikologiju, Zagreb, Zaklada Friedrich Ebert, 2006, 148.

${ }^{10}$ Usp. Lulu RODRIGUEZ, Daniela V. DIMITROVA, The levels of visual framing, Journal of visual literacy, 30 (2011) 1, 48-65, 49.

${ }^{11}$ Cornelia BRANTNER, Katharina LOBINGER, Irmgard WETZSTEIN, Effects of visual framing on emotional responses and evaluations of news stories about the Gaza conflict 2009, Journalism \& Mass Communication Quarterly, 88 (2011) 3, 523-540, 526.
} 
narativ i priča vizualno uokviruju i pomažu, prema nekim istraživanjima, ${ }^{12}$ kvalitetnoj percepciji stvarnosti. To najčešće nastaje zbog nametljivosti vizualne opreme u odnosu na tekstualnu te ona sama po sebi, svojim znakovljem i ostalim semiotičkim elementima, stvarnost čini uvjerljivom, ali i pamtljivom za različite medijske publike. ${ }^{13}$ No, neetičnim korištenjem vizualnih elemenata, stvarnost se može iskriviti i izazvati fenomen medijske konstrukcije, a ne prikaza društvene stvarnosti. Medijski okviri medijskim publikama ne mogu posve nametnuti, ali mogu usmjeriti tijek kojim će se društvena rasprava odvijati te koje će teme biti dominantnije od drugih u širim kontekstima, poput medijskog, političkog, kulturalnog i općedruštvenog. Upravo u tom segmentu, neizostavno je definirati mjesto i važnost te ulogu etike vizualne komunikacije i narativa u digitalnom dobu.

Etika u vizualnoj kulturi i vizualnim medijima ima veliku ulogu te nije statična jer izravno utječe na način djelovanja pojedinca u društvu, ponajviše kroz međusobnu interakciju i interpersonalnu komunikaciju. U kontekstu medija, riječ je i o medijskoj etici koja regulira načine uporaba komunikacijskih sredstava i medijima posredovanih poruka. Ipak, pri recepciji vizualnih medijskih sadržaja nužno je i razumijevanje, a potom prijenos značenja koje vizualna poruka prenosi i ima u društvu. Zbog važnosti značenja u cjelokupnoj vizualnoj kulturi, pa onda i u vizualnim medijima, neizostavan je i pojam vizualne (medijske) etike koja povezuje sve navedene sposobnosti i načine recepcije i razumijevanja te određuje prijenos značenja koje poruka ima i kako može biti shvaćena te koliko se značenja mogu i razlikovati zbog prije navedene interakcije i društvenih različitosti svake osobe. ${ }^{14}$ Opisana etika terminološki se koristi i kao vizualna etika, odnosno zaseban dio etike koji se bavi područjem proučavanja vizualnosti u kulturi, medijima i komunikaciji. Također, vizualna etika uključuje i proučavanje svih ispravnih i neispravnih te etički upitnih djelovanja u području izražavanja slikom, korištenja slike i recepcije slike kao osnovnog vizualnog sredstva komunikacije i jednog od temelja vizualne kulture. Isto tako, uključuje i obilježja koja povezuju sve vrste medija, a posebice $\mathrm{u}$ digitalnom dobu, u kojem je vizualnost i etika izrazito značajna i česta tema brojnih društvenih rasprava zbog snažnog i brzog mogućeg utjecaja na korisnike, odnosno primatelje medijskih sadržaja i cijele medijske publike. ${ }^{15}$ Stoga se od početnog pojma etike fotografije, koji nije bio dostatan za pojašnjavanje svih

\footnotetext{
${ }^{12}$ Usp. Juhani PALlASMAA, Design for Sensory Reality: From Visuality to Existential Experience, Architectural Design, 89 (2019) 6, 22-27; Rodriguez, Dimitrova, The levels of visual framing..., 49-51.

${ }^{13}$ Usp. Rodriguez, Dimitrova, The levels of visual framing..., 50-53.

${ }^{14}$ Wilkins LEE, Clifford G. CHRISTIANS (ur.), The Routledge Handbook of Mass Media Ethics, New York - London, Routledge, 2020, 118-119.

${ }^{15}$ Smith i dr. (ur.), Handbook of visual communication..., 433-435.
} 
etičkih prijepora unutar vizualnih komponenti medija, on proširio na pojam vizualne etike ili etike vizualnosti. ${ }^{16}$

Prije samog definiranja i pojašnjavanja vizualnoga narativa i njegove poveznice s etikom u digitalnom dobu, nužno je bilo pojasniti osnovne termine koji se vežu uz vizualnost u medijima i čitavu vizualnu kulturu. Dakle, mediji kroz narativ svojim publikama »pomažu« u razumijevanju okoline, društvene stvarnosti i formiranja stava o aktualnim događajima. ${ }^{17}$ Vizualni narativ podrazumijeva svaku priču, odnosno slijed događaja povezanih uzrokom i posljedicom kao vezom koja u središtu ima obilježje pripovijedanja kroz vizualne elemente. Neki od najčešćih elemenata su slike, fotografije, ilustracije i sl. radi slanja poruke, a u ovom kontekstu putem masovnih medija i koristeći vizualne elemente kao temeljne i glavne alate komunikacije i odašiljanja poruke medijskim publikama. ${ }^{18}$

Vizualni narativ također pridonosi različitostima u interpretaciji kod primatelja medijskih sadržaja jer nekorištenjem tekstualnog elementa, vizualni elementi u medijskom narativu ostavljaju prostor za brojne interpretacije koje ponekada uopće ne moraju biti povezane s temeljnim ciljevima i svrhom odašiljanja vizualne medijske poruke od strane pošiljatelja, odnosno masovnog digitalnog medija. ${ }^{19} \mathrm{U}$ ovom kontekstu nužno je spomenuti i vizualnu retoriku prema kojoj se neki medijski sadržaj može prikazati samo kroz vizualni narativ, a postići u nekim slučajevima čak i snažniji odjek kod medijskih publika, odnosno u javnosti. ${ }^{20}$ Takav vizualni narativ bitan je element i u percepciji medijski konstruirane stvarnosti. Prema Hromadžiću, utjecaji na razumijevanje društvene stvarnosti, kako medijskog prikaza tako i medijske konstrukcije, kod primatelja mogu biti općenite javne politike i načini funkcioniranja medija, potom različiti interesi, ponajviše u sferi ekonomije i financija, a zatim i kulture. Ipak, krajnji medijski proizvod vizualnih narativa je upravo onaj koji barem približno, ako ne posve, odgovara na zahtjeve svih navedenih čimbenika kao dionika koji utječu na način razumijevanja stvarnosti kod medijskih publika. ${ }^{21}$

U vizualnom medijskom narativu jedan od najistaknutijih elemenata je fotografija - snažno sredstvo odašiljanja poruka koja sama po sebi, posredstvom

\footnotetext{
${ }^{16}$ Clifford G. CHRISTIANS, Media Ethics and Global Justice in the Digital Age, Cambridge, Cambridge University Press, 2019, 5.

${ }^{17}$ Viktorija CAR, Leali OSMANČEVIĆ, Televizijski narativi - pričam ti priču, Sarajevski žurnal za društvena pitanja/Sarajevo Social Science Review, 5 (2016) 1-2, 7-27, 9.

${ }^{18}$ Usp. Sarah E. DRAW, Rony E. DUNCAN, Susan M. SAWYER, Visual storytelling. A beneficial but challenging method for health research with young people, Qualitative health research, 20 (2010) 12, 1677-1688, 2-6; DOI:10.1177/1049732310377455.

${ }^{19}$ Dawn MANNAY, Visual, narrative and creative research methods. Application, reflection and ethics, New York - London, Routledge, 2016, 64-66.

${ }^{20}$ Brian L. OTT, Robert L. MACK, Critical media studies. An Introduction, New York, John Wiley \& Sons, 2020, 139.

${ }^{21}$ Usp. Hajrudin HROMADŽIĆ, Medijska konstrukcija društvene zbilje, Zagreb, AGM, 2014, 27 28.
} 
masovnih, posebice digitalnih poruka, može poslati snažniju poruku različitim medijskim publikama nego tekstualni narativ. Stoga je u ovom kontekstu neizostavno osvrnuti se na semiotiku fotografije. Semiotika je znanost koja se bavi proučavanjem znakova, simbola, kodova i mitova, a fotografija ima značajnu ulogu te se može koristiti i interpretirati u različitim medijsko-društvenim okolnostima. Prije svega, riječ je o fotografiji kao elementu za stvaranje javnoga mnijenja, potom uporabi fotografije radi izvještavanja o svakodnevnim događajima koji će, upravo zbog istaknutog obilježja vizualnosti, široj publici dočarati događaj, te korištenje fotografije radi promocije i oglašavanja - industrije koja na svjetskoj razini sve češće koristi upravo taj vizualni element zbog brojnih istraživanja javnoga mnijenja koja su pokazala da je uporaba fotografije izrazito učinkovita za privlačenje pozornosti i porast interesa primatelja vizualnih medijskih sadržaja u digitalnom dobu. ${ }^{22}$

\section{Vizualna pismenost u digitalnom dobu}

Vizualna pismenost $u$ doba digitalnih medija važna je vještina svih odgovornih građana i primatelja medijskih sadržaja. Budući da se terminološki vizualna pismenost razvila iz pojma vizualne kulture, nužno ju je najprije promatrati kroz kulturološku prizmu, a potom i širu društvenu. Naime, vizualna komunikacija i njezino tumačenje, tj. vizualna pismenost jest univerzalna, za razliku od interpretacije vizualnih medijskih sadržaja koja je individualizirana. Digitalna tehnologija i digitalni medijski napredak omogućili su brži i disperzivniji, odnosno raspršeniji i diferenciraniji pristup vizualnim medijskim sadržajima svim primateljima, bez obzira na njihove različitosti. Pristup različitim vizualnim sadržajima omogućuje i različite vizualne interpretacije kod medijskih publika. ${ }^{23}$

U modernom, suvremenom i digitalnom društvu medijski tekstovi se uglavnom čitaju vizualno, a tek onda tekstualno, što je još jedan od značajnih indikatora važnosti vizualne pismenosti zbog sveprisutnosti vizualnosti kao obilježja svih masovnih medija, posebice digitalnih. Izražavanje bilo koje masovnomedijske poruke danas je gotovo nezamislivo bez vizualne opreme, dok je za njezino razumijevanje nužna neka vrsta edukacije iz vizualne pismenosti. Zbog toga se u komunikološkoj terminologiji počeo koristiti naziv fenomen vizualnog registra, odnosno pojave da je medijskim publikama važnije vidjeti nego

\footnotetext{
${ }^{22}$ Usp. Göran SONESSON, Semiotics of photography. The state of the art, u: Peter Pericles TRIFONAS (ur.), International Handbook of Semiotics, Springer, Dordrecht, 2015, 421-426.

${ }^{23}$ Usp. Emery LEE, Adele FLOOD, Visual Literacy, u: Julie DYSON (ur.), More than words can say. A view of literacy through the arts, Queensland, Australia, The National Advocates for Arts Education (NAAE), 2019, 21-26.
} 
čuti neki medijski sadržaj te je zbog toga i sam koncept slike kao dijela vizualne komponente postao osnovni, a ne sporedan element medijskih sadržaja. ${ }^{24}$

Vizualna pismenost se definira na različite načine, ali $\mathrm{s}$ istim temeljima. Ponajprije kao niz vizualnih kompetencija koje, jednom usvojene, primatelju omogućuju ispravnu interpretaciju vizualnih medijskih sadržaja. Također, vizualnu pismenost čine razvijene sposobnosti razlikovanja, povezivanja i razumijevanja vizualne komunikacije kao sastavnoga dijela vizualne kulture. U interpersonalnoj komunikaciji ona je nužno sredstvo za razumijevanje poruke poslane putem masovnih medija do različitih medijskih publika koje, na temelju dobivene poruke i vizualne opismenjenosti, imaju prostor za vlastitu interpretaciju sadržaja. ${ }^{25}$

Vizualna pismenost $u$ znanstvenoj i stručnoj literaturi ima više definicija i brojna obilježja. Uz već navedeno, neke od njih nabrajaju niz mentalnih kompetencija koje prije svega jačaju kognitivni razvoj pojedinca, a potom i sposobnost, odnosno vještinu konstruiranja slike, odnosno vizualnog sadržaja radi pojašnjavanja vizualnih medija koji kreiraju i medijsko-vizualnu stvarnost. ${ }^{26}$ Vizualna pismenost primateljima medijskih sadržaja pomaže čitati slike i različite vizualne medijske materijale osposobljavajući ih za prepoznavanje i razvijanje kritičke percepcije vizualnih sadržaja. Nužno je razumjeti prvotnu nakanu odašiljanja vizualnog sadržaja, ali i krajnjega cilja pošiljatelja. Takva vrsta kompetencije terminološki se naziva vizualnom kompetencijom, a ona je preduvjet vizualne pismenosti i razvijenih tehnika vizualnog iščitavanja sadržaja, posebice u digitalnome dobu kada je vizualnost u svome usponu. ${ }^{27}$

\section{Vizualna antropologija i odgovornost medijskih publika - novi etički izazovi}

Medijske publike su u digitalnom dobu raspršene ponajviše zbog promjene interesa, očekivanja i navika pri korištenju novih, ali i tradicionalnih medija. Kada je riječ o vizualnim sadržajima, u posljednjih nekoliko desetljeća medijske su publike doživjele brojne promjene uvjetovane psihološkim čimbenicima kao i promjenama u komunikacijskim procesima s naglaskom na povratnu informaciju (eng. feedback) koja im omogućuje aktivno i izravno sudjelovanje u

\footnotetext{
${ }^{24}$ John HARTLEY, Communication, cultural and media studies. The key concepts, New Yoek London, Routledge, 2019, 108.

${ }^{25}$ Usp. Vera TURKOVIĆ, Vizualna/likovna (ne)pismenost političkih stranaka u Hrvatskoj, Politička misao - časopis za politologiju, 46 (2009) 1, 114-134, 115-116.

${ }^{26}$ Ken L. SMITH, Sandra MORIARTY, Gretchen BARBATSIS (ur.), Handbook of Visual Communication. Theory, Methods, and Media, New Jersey - London, Mahwah - Lawrence Erlbaum Associates, 2005, 483.

${ }^{27}$ Thomas W. J. MITCHELL, Visual literacy or literary visualcy?, u: James ELKINS (ur.), Visual Literacy, New York - London, Routledge, 2009, 11-14.
} 
nekom medijskom sadržaju, a posebice vizualnom, s obzirom na to da upravo takav sadržaj pobuđuje najveći interes. ${ }^{28}$

Govoreći o vizualnom medijskom narativu, medijske publike su u njega uključene na više razina, a ponajviše na kognitivnoj i emocionalnoj, na temelju kojih izražavaju mišljenja i donose zaključke. Vizualnost se u tom kontekstu najviše odražava kroz likove i radnje u kojima ti likovi sudjeluju te za koje se medijske publike na neki način vezuju, odnosno ostvaruju takozvane pseudopovezanosti.

U takvoj vrsti interakcije, najsnažniji okidač je televizija, kao jedan od najraširenijih vizualnih medija. Često dolazi do nastanka multidimenzionalne identifikacije, odnosno poistovjećivanja s vizualno prikazanim likovima i njihovim radnjama unutar različitih formata putem kojih medijske publike donose odluke o nastavku praćenja takvih vizualnih sadržaja. Iako utjecaj medijskih sadržaja na neke medijske publike nije mjerljiv (osim u longitudinalnim detaljnim studijama), dokazano je da vizualna povezanost s likovima i radnjama može, uz ostale čimbenike, imati utjecaj na percepciju stvarnosti kod medijskih publika. ${ }^{29}$

Vizualna antropologija bitan je element vizualne i digitalne tehnologije, posebice jer vizualnost antropologiji, uza sva prije spomenuta obilježja, daje kritičnost $u$ razumijevanju aktualnih društvenih pojava te doprinosi izgradnji vizualnog antropološkog znanja. Vizualnost u digitalnom dobu usko je povezana s hipertekstualnošću koja vizualnost stavlja u prvi plan te na njoj temelji poimanje i značenje u vizualnoj masovnoj komunikaciji. ${ }^{30} \mathrm{U}$ počecima vizualne antropologije, središte istraživanja bilo je na fotografiji i filmu. Poslije se termin vizualne antropologije proširio na opis i analizu vizualne kulture i vizualnih medija. ${ }^{31}$ Od tada su antropolozi, a kasnije i drugi znanstvenici vezani uz medijske i komunikacijske studije, vizualnost proučavali radi razumijevanja, opisivanja i dekodiranja vizualnih medijskih poruka i načina na koje ih različite medijske publike interpretiraju. ${ }^{32}$ Vizualni jezik u medijskom narativu odnosi se na interpretaciju slika i ostalih vizualnih materijala koji se koriste $\mathrm{u}$ različitim medijskim formatima radi informiranja javnosti. Proučavanjem vizualnosti dolazi se i do termina znanstvene vizualizacije koji se odnosi na

${ }^{28}$ Hélène JOFFE, The power of visual material. Persuasion, emotion and identification, Diogenes, 55 (2008) 1, 84-93, 88-89.

${ }^{29}$ William J. BROWN, Examining four processes of audience involvement with media personae: Transportation, parasocial interaction, identification, and worship, Communication Theory, 25 (2015) 3, 259-283, 261-263.

${ }^{30}$ Sarah PINK, The future of visual anthropology. Engaging the senses, Routledge, Taylor \& Francis, 2006, 19-20.

${ }^{31}$ Usp. David MacDOUGALL, How the Visual Makes Sense,Visual Anthropology, 33 (2020) 1, 1-8.

${ }^{32}$ Kirsten DROTNER, Media audience practices beyond living memory. Modeling theoretical and methodological issues, Participations - Journal of Audience and Reception Studies, 16 (2019) 2, 327-349, 333. 
vizualnu interakciju među medijskim publikama u svakodnevnoj komunikaciji radi osnaživanja vještina koje im pomažu u razumijevanju različitih vizualnih reprezentacija nekog sadržaja. Razvojem vizualne pismenosti medijske publike razvijaju i jačaju postojeće tehnike vizualne interpretacije koja uključuje niz procesa potrebnih za identificiranje vizualnih masovno-medijskih poruka i logičkog te kritičkog zaključivanja vezanog uz njihovo značenje i krajnji cilj. ${ }^{33}$

\section{Zaključak}

U digitalnom dobu masovne medije i masovno posredovane poruke nemoguće je proučavati bez obilježja vizualnosti koje je temeljno za privlačenje različitih medijskih publika i praćenje promjena u njihovim interesima, očekivanjima i navikama u korištenju medijskih sadržaja. Etičke implikacije pri analizi vizualnih medijskih poruka od velike su važnosti koliko za samu znanost toliko i za struku i praksu, s naglaskom na medijske publike čija je interpretacija uvjetovana nizom društvenih, kulturalnih i drugih čimbenika. Etika vizualnih medijskih sadržaja sastavni je dio razumijevanja vizualne kulture i antropologije te različitih načina korištenja vizualnih medijskih sredstava u medijima, $\mathrm{s}$ naglaskom na one digitalne. Razvilo se i područje vizualne etike koja se bavi proučavanjem etički prihvatljivih vizualnih narativa u masovno-medijski posredovanim porukama i prepoznavanjem etički neprihvatljivih oblika vizualne kulture. U 21. stoljeću vizualnost u medijima sastavni je dio medijskih i komunikacijskih studija, posebice u kontekstu vizualne kulture i vizualne antropologije. Uz medijsku i informacijsku pismenost, za odgovorne građane i razvoj te napredak svih demokratskih društava neizostavna je vizualna pismenost koja proizlazi iz vizualne kulture i vizualnog framinga pomoću kojeg društvo jača interpretacijske kompetencije pri iščitavanju digitalno-vizualnih medijskih sadržaja kao i razumijevanje vizualne opreme kao jednog od temeljnih alata medijskih sadržaja digitalne ere. Proučavajući vizualnost u medijima, pozornost medijskih publika uglavnom privlači upravo vizualno obilježje medijskih sadržaja te je stoga neizostavno u suvremenom društvu znati čitati, interpretirati i razumjeti vizualne medijske sadržaje. Vizualna pismenost je, uz medijsku i informacijsku, postala jedna od neizostavnih vještina 21. stoljeća.

\footnotetext{
${ }^{33}$ Richard LOWE, Visual Literacy in Science and Technology Education, Connect. UNESCO International Science, Technology \& Environmental Education Newsletter, 25 (2000) 2, 1-3.
} 


\section{Leali Osmančević* \\ From Visual Culture to Visual Literacy - Visuality in the Media and Ethical Responsibility of Media Audiences in the Digital Age \\ Summary}

Visuality is one of the main features of sending a message from the sender to the recipients of information and visual content in the digital age. Therefore, the visual media narrative itself is a current topic in the digital age, due to its speed, human affection for the visual content and overall perception of social reality based on visuality. Following the above, the question arises, the role and importance of ethics in the visual transmission of information, as well as the development of visual literacy of media audiences. Due to different interests, media audiences, with the aim of a more responsible approach to understanding visual media content, are encouraged to develop the ability of visual literacy, with related media information literacy (MIL). The paper will explain the basic concepts of visual culture, visual media and visual framing, as well as the role of media audiences in understanding and distinguishing the media presentation of social reality from media constructed realities. The importance of integrating ethics in the process of transmitting and receiving visual media content, which, with the help of various components, contribute to the strengthening of responsibility and the progress of society, will also be questioned.

Key words: ethics, media audiences, visual culture, visual literacy, visual narrative.

(na engl. prev. Leali Osmančević)

\footnotetext{
* Leali Osmančević, mag. comm., Teaching and Research Assistant, Catholic University of Croatia, Department of Communicology; Address: Ilica 242, HR-10000 Zagreb, Croatia; E-mail: leali.osmancevic@unicath.hr.
} 